\title{
MARCADORES SOROLQ́GICOS DA HEPATITE POR VíRUS B (HVB): A DETECÇĀO DE ANTI-HBCAg EM INDIVIDUOS HBSAg NEGATIVOS COMO SINAL DE ALERTA NA HEPATITE POR VÍRUS B PÓS-TRANSFUSIONAL
}

\author{
MARTA MUTSUMI ZAHA-INOUYE 1 \\ EDNA MARIA VISSOCI REICHE 1 \\ RUBENS PONTELLO1
}

\begin{abstract}
INOUYE, M.M.Z; REICHE, E.M.V.; PONTELLO, R. Marcadores sorológicos de hepatite por virus B (HVB): a deteç̧āo de anti- $\mathrm{HBcAg}$ em indivíduos $\mathrm{HBsAg}$ negativos como sinal de alerta na hepatite por virus B pós-transfusional. Semina: Ci. Biol./Saúde, Londrina, v. 13, n. 2, p. 102 - 104, jun. 1992.
\end{abstract}

\section{RESUMO}

Os autores analisaram os resuitados obtidos da pesquisa de marcadores sorol6gicos do víns da hepatite $B$ (VHB) em 127 amostras de soro de individuos em regimo de reclusắo na $10^{2}$ Subdivisăo Policial do Distrito de Londrina, Paraná, com o objetivo de determinar a frequência de positividade destes marcadores nesta amostra e identificar quais marcadores seriam úteis na seleção de candidatos a doadores de sangue. A deteç̧ăo de $\mathrm{HBSAg}$, $\mathrm{HBOAg}$, antj-HBsAg, anti-HBcAg e anti-HBeAg foi pelo método de radioimunoensaio de fase solida (ABBOTT Laboratories). Além da presença do marcador HBsAg em cinco amostras detectśveis normalmente pela sorologia de rotina dos bancos de sangue, dois outros perfis sorológicos HBsAg negativos foram detectados: anti-HBcAg em sete amostras e anti-HBcAg + anti-HBeAg associados em uma amostra, totalizando 13 amostras que poderiam ser potencialmente infectantes para um receptor num procedimento transfusional.

PALAVRAS-CHAVE: Virus da Hepatite B; HBsAg; Anti-HBcAg; Hepatite pós-transfusional.

\section{1 - INTRODUÇĀO}

PONTELLO et al (1985); FIGUEIREDO-MENDES et al (1988) e AMATO NETO \& BALDY (1989), relatam que a interaçäo do virus da hepatite $B$ (VHB) com o hospedeiro humano proporciona uma gama de resposta imunológica detectada pelo aparecimento, no soro, de diferentes marcadores: $\mathrm{HBsAg}$, antígeno glicoprotéico de superfície que aparece no soro mesmo antes do quadro clfnico e vai declinando progressivamente até $03^{\circ}$ ou $4^{\text {}}$ mês, quando deixa de ser detectado, não sendo identificado no início da doença em $10 \%$ dos casos, percentual que sobe para $30 \%$, ao término do primeiro mês; HBcAg, antígeno de "core", nāo detectado no soro de indivíduos com infecç̌̆o agura ou crônica pelo VHB, embora seja encontrado em núcleo de hepatócitos de potadores de hepatite aguda e crônica, bem como em pacientes em estado de alteraçăo imunológica e portadores sāos: $\mathrm{HBeAg}$, antígeno năo particulado, marcador de patogenicidade e infectividade, considerado um índice de síntese viral, podendo ser demonstrado no soro durante a fase de incubaçāo e no início da hepatite por vírus $B$, em doentes com HBsAg, persistindo nos casos que desenvolvem hepatite crônica.

Em resposta a estes marcadores antigênicos, o hospedeiro sintetiza anticorpos especfficos que podem ser de- tectados no soro atravếs de técnicas sensíveis como o radioimunoensaio e o enzimaimunoensaio: anti-HBsAg, que representa o indice de imunidade e resoluçăo da doença; anti $\mathrm{HBCAg}$, marcador confiável de replicaçăo viral, demonstrado no soro a partir das evidências de alteraçōes clínico-laboratoriais da doença e anti-HBeAg, sendo que seu aparecimento sugere um bom prognóstico.

Dentre os diferentes modos de transmissão da hepatite por virus $B$ (HVB), que pode ser horizontal através de fluídos e secreçōes, como também vertical, da māe para o filho, no útero, durante ou após o parto a transmissão sanguínea é uma das formas mais comuns. A transmissāo da hepatite por virus $B$ pode ser prevenida através da realizaçāo prévia de exames sorológicos dos candidatos a doadores de sangue. O marcador sorológico mais comumente utilizado pelos bancos de sangue para a seleçäo prévia de candidatos é o HBsAg. No entanto, a presença de outros marcadores sorológicos como o anti-HB$\mathrm{CAg}$ detectado isoladamente, sendo indicativo de replicação viral ou anti-HBeAg e anti-HBcAg associados constituem importantes parâmetros indicativos de risco potencial na transmissão da HVB pós-transfusional.

SARNO et al (1977), estudando pacientes portadores de hepatite agura e crônica em hemodialisados crônicos, detectaram 6 casos com anti-HBcAg na ausência de $\mathrm{HB}$ -

1 - Docentes de Imunologia Clínica do Departamento de Patologia Aplicada, Legislaçäo a Deontologia, Centro de Ciências da Saúde, Universidade Estadual de Londrina, Londrina, Pr., Setor de Imunologia Cilnica/Radioimunoensaio do Laboratório de Análises Cifnicas do Hospital Universitário Regional do Norte do Paraná. 
SAg no soro, recomendado a pesquisa de ambos os marcadores para afastar a infeç̧ăo pelo $\mathrm{VHB}$.

HOOFNAGLE et al (1978), evidenciando que doadores de sangue apresentavam anticorpos anti-HBcAg sem a presença de HBsAg e anti-HBsAg, sugeriram que sangues anti-HBcAg reagentes poderiam ser infecciosos e transmitir a HVB. GERLICH et al $\{1980\}$, detectaram anticorpos IgM anti-HBcAg em $8(5,6 \%)$ entre 142 doadores de sangue $\mathrm{HBSAg}$ negativos com niveis elevados de transaminases séricas e em $11(0,5 \%)$ dos 2.400 doadores HBsAg negativos com niveis normais de transaminases sericas, sugerindo ser 0 anticorpo IgM anti-HBcAg meIhor indicador de HVB que o HBsAg.

\section{2 - OBJETIVOS}

O presente estudo tem como objetivos determinar a frequência de positividade dos marcadores sorológicos do $\mathrm{VHB}$ em soros de individuos em regime de reclusāo na 10 - Subdivisāo Policial (10 SDP) do Distrito de Londrina e identificar outros marcadores, alem do HBsAg, importantes para prevenção da HVB pós-transfusional.

\section{3 - MATERIAL E MÉTODOS}

Foram analisadas amostras de soros de 127 individuos em regime de reclusão na $10^{\text {a }}$ Subdivisão Policial do Distrito de Londrina, Paraná. Esta populaçāo, por suas caracteristicas diferenciadas quanto aos fatores sociais e ambientais, apresentaram dados epidemiológicos que justificaram a predisposiçäo ao contágio pelo $\mathrm{VHB}$, como a promiscuidade e o uso de drogas endovenosas. Foram pesquisados os marcadores sorológicos $\mathrm{HBsAg}, \mathrm{HBeAg}$, anti-HBsAg, anti-HBcAg e anti-HBeAg pelo método de radioimunoensaio em fase sólida da Abbott Laboratories.

\section{4 - RESULTADOS}

Os resultados obtidos são apresentados nas Tabelas 1 , $2,3 e 4$.

TABELA 1 - FREQUENCLA DA POSITIVIDADE. DE PELO MENOS UM MARCADOR SOROLÓGICO DO VBH NAS AMOSTRAS PROVENIENTES DE 127 INDIVIDUUOS EM REGIME DE RECLUSĀO NA $10^{\text {a }}$ SDP DO DISTRITO DE LONDRINA, PR.

\begin{tabular}{lcc}
\hline Resultado & No de Casos & Porcentagem \\
\hline Reagente & 59 & 46,5 \\
Não Reagente & 68 & 53,5 \\
\hline TOTAL & 127 & 100,0 \\
\hline
\end{tabular}

TABELA 2 - FREQUENCIA DA POSITIVIDADE ISOLADA DOS MARCADORES SOROLÓGICOS EM AMOSTRAS PROVENIENTES DE 127 INDIVIDUOS EM REGIME DE RECLUSĀO NA $10^{*}$ SDP DO DISTRITO DE LONDRINA.

\begin{tabular}{lcc}
\hline $\begin{array}{l}\text { Marcadores } \\
\text { Sorologicos }\end{array}$ & No de Casos & Porcentagem \\
\hline HBsAg & 05 & 3,9 \\
HBeAG & 02 & 1,6 \\
Anti-HBsAg & 44 & 34,7 \\
Anti-HBcAg & 54 & 42,5 \\
Anti-HBeAg & 22 & 17,3 \\
\hline TOTAL & 127 & 100,0 \\
\hline
\end{tabular}

TABELA 3 - FREQUENCIA DA POSITIVIOADE ISOLADR E ASSOCIADA DOS MARCADORES SOROLÓGICOS EM 127 AMOSTRAS PRO. VENIENTES DE INDIVIDUOS EA REGIME DE RECLUSÄO NA 10 SOP DO DISTNITO DE LOHDRINA

\begin{tabular}{|c|c|c|}
\hline $\begin{array}{l}\text { Atercadoras } \\
\text { Sorokgicos }\end{array}$ & $\mathrm{N}^{2}$ do Ceeos & Porcentegem \\
\hline 1. Nanhum & 68 & 53,5 \\
\hline 2. $\mathrm{Amti}-\mathrm{HB} s+\mathrm{Amti}-\mathrm{HB} \mathrm{c}$ & 22 & 173 \\
\hline 3. Anti-HBa + Antl-HBc + Anzi-HBo & 17 & 13,4 \\
\hline 4. Anti-H\&c & or & 5,5 \\
\hline 5. Anti-HBs & DS & 39 \\
\hline 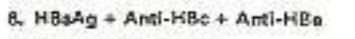 & $a$ & 3,1 \\
\hline 2. $\mathrm{HBQAg}+\mathrm{Ant}-\mathrm{HBC}$ & 02 & i. \\
\hline 8. $\mathrm{HBSAg}+\mathrm{Ant} \cdot \mathrm{HBC}$ & or & O., B \\
\hline B. Anti-HEn + Anti-HBc & 01 & 0.8 \\
\hline TOTAL & 123 & 10000 \\
\hline
\end{tabular}

TABELA 4 - COMPORTAMENTO DOS MARCADORES SORGLOGICOS DE HEPATITE POR VIRUS E EM 13 AMOSTRAS DE SORO DE IN. DIVIDUOS CONSIOERADOS POTENCIAL MENTE INFECTAN. TFS.

\begin{tabular}{|c|c|c|}
\hline HBथA (REAGENTE) & $M^{2}$ de Cneas & Porcantagem \\
\hline$H B=\Omega_{B}+$ Anti-HBC & 01 & 7,7 \\
\hline$H B=A_{a}+A n d-H B C+A r n i-F B n$ & 04 & 308 \\
\hline SUE-TOTAL & 05 & 38,5 \\
\hline \multicolumn{3}{|l|}{ HEEAQ (NĀO REAGENTE] } \\
\hline$A n U-H B v+A_{m} t^{2}-H a c$ & 02 & 77 \\
\hline AntI-HBc & 07 & 53,8 \\
\hline SUB-TOTAL & 08 & 61.5 \\
\hline TOTAL & 13 & 1000 \\
\hline
\end{tabular}




\section{5 - DISCUSSÄO}

A tabela 1 apresenta a frequência de positividade para os marcadores sorológicos do HBV nas amostras provenientes de 127 individuos analisados. Destes, 59 apresentaram reatividade para, pelo menos, um dos marcadores analisados.

De acordo com a Tabela 2, observamos que na amostra estudada o HBsAg foi detectado em 5 individuos $\langle 3,8 \%)$, confirmando a maior incidência do VHB na populaçăo de presidiários, em relação à população regional que, segundo PONTELLO et al (1985), apresentou $0,6 \%$ de positividade; $\mathrm{HBeAg}$ em $2(1,6 \%)$, anti-HBsAg em 44 $(34,7 \%)$, anti-HBcAg em $54(42,5 \%)$ e anti-HBeAg em 22 $(17,3 \%)$. Os anticorpos anti- $\mathrm{HBcAg}$ indicam contato prêvio com o VHB, enquanto que a presença do $\mathrm{HBsAg}$ e $\mathrm{HBeAg}$ indicam infecçāo viral.

Com relaçāo aos dados apresentados na Tabela 3 , observa-se que das 127 amostras analisadas, $68(53,5 \%)$ nâo apresentaram nenhum marcador sorológico que revelasse o comprometimento do indivíduo com o VHB; 22 $\{17,3 \%\}$ individuos apresentaram anti-HBsAg e anti-HBcAg associados; $17(13,4 \%)$ com anti-HBsAg + anti$\mathrm{HBeAg}$ associados, $7(5,5 \%) \mathrm{com}$ anti-HBcAg e $5(4 \%)$ com anti-HBsAg isolados, caracterizando nestes individuos uma resposta imunológica especifica frente a um contacto com o VHB. O marcador HBsAg foi detectado em cinco amostras, sendo estes indivíduos considerados potencialmente infectantes e excluídos para a doação de sangue. Mas ao analisarmos o comportamento dos marcadores sorológicos nos indivíduos HBsAg negativos, conforme está demonstrando a Tabela 4 , observamos que 8 amostras de soro apresentaram o marcador anti$\mathrm{HBcAg}$ isolado ou associado ao anti-HBeAg. Sendo o anti-HBcAg um parâmetro de replicaçăo viral, estes individuos, apesar de serem HBsAg negativos, seriam considerados potencialmente infectantes para um receptor em um procedimento transfusional. Na realidade, entre as 127 amostras analisadas, 13 pertenceriam a indivíduos potencialmente infectantes.

\section{6 - CONCLUSĀO}

A análise dos dados obtidos, além de reforçar os já apresentados em literatura, indicam a necessidade da inclusäo da pesquisa de outros marcadores sorológicos do VHB, como o anti-HBcAg da classe $\lg M$, na seleçäo de candidatos a doadores de sangue. Com este procedimento, objetivamos ampliar a segurança e qualidade do sangue a ser transfundido, contribuindo para a prevençäo da HVB pós-transfusional.

INOUYE, M.M.Z; REICHE, E.M.V.; PONTELLO, R. hepatites B virus serological markers: anti-HBcAg detection in lacking HBsAg individuais as potential risk in the post-transfusion hepatitis b virus. Semina: Ci. Biol./Saúde, Londrina, v. 13, n. 2, p. $102-104$, june 1992.

\section{ABSTRACT}

Serological markers for hepatitis B virus were analysed in 127 blood samples from prisoners of the 10th Police Substation in the district of Londrina, Parana, for the purpose of selecting blood donors. Antigeno of HBs and HBe as well as antibodies to HBS, $\mathrm{HBe}$ and $\mathrm{HBC}$ were measured by radioimmunoessay (Abbott Laboratories). In addition to the presence of HBs Ag in 5 samples, which would be detected by normal blood bank routine, $8 \mathrm{HBsAg}$ nogative samples gave HBC-antibody positive tests in 7 and antibodies to both $H B C$ and $H B e$ in one case, totalizing 13 samples which were potentially infectious to a blood transfusion receptor. The importance of searching, not only for $H B \triangle A g$ but also for the antibody to HBc, is stressed for the prevention of post-transfusional hepatitis.

KEY-WOADS: Hepatitis B Virus; HBSAg, Anti-HBcAg; Post-transfusion hepatitis.

$$
\text { , }
$$

AMATO NETO, V.; BALDY, J.L. daS. Doenças Transmissiveis. 3. ed. Săo Paulo: Sarvier, 1989. 929p.

FIGUEIREDO-MENDES, T. et al. História natural da

hepalite. Casa do Rio de Janeiro. Moderna Hepatologia:

Boletim do Serviço de Hepatologia da Santa Casa, Rio de

Janeiro, v. 13, n. 2, p. 1-39, maio 1988.

HOOFNAGLE, J.H. et al. Type B hepatitis after transfusion with blood containing antibody to hepatitis $\mathrm{B}$ core antigen. The New England Joumal of Medicine, v. 298, n. 25, p. 1380-1383, jun. 1978.

GERLICH, W.H. LUER, W. Diagnosis of acute and inapparente hepatitis $B$ virus infections by measurement of IgM antibody to hepatitis B core antigen. The Joumal of infections Diseases, v. 142 , n. 1, p. 95-101, jul. 1980.
Recebido para publicaçăo em 13/11/1991

Semina Ci. Biol./Saúde, Londrina, v. 13, n. 2, p. 102 - 104, jun. 1992 